\title{
Enzyme Electrophoresis in Shrimps by Polyacrylamide Gel for Phylogeny: A Practical Guide
}

\author{
Abolfazl Bayrami. M(Corresponding author), V. Shakunthala \& S. R. Ramesh \\ Department of Studies in Zoology, University of Mysore, Mysore- 06, India \\ Tel: 91-99-8624-4057Ｅ-mail: abolfazlbayrami@gmail.com
}

\begin{abstract}
Polyacrylamide electrophoresis gel for studying multilocus enzyme uses the relative electrophoretic mobilities of intracellular enzymes to characterize and differentiate organisms by generating an electromorph type. There are many articles for enzyme electrophoresis by using starch gel but there is lacuna by using polyacrylamide gel especially in shrimps. This article presents the chemical conditions for some enzyme that may be useful, a guide to the successful practice of the electrophoretic technique, by using polyacrylamide gel in shrimps.
\end{abstract}

Keywords: Polyacrylamide electrophoresis gel, Enzyme, Shrimps

\section{Introduction}

Enzyme electrophoresis is a method for studying genetic polymorphism at a number of enzyme loci enables us to characterize a strain or a species (Ausubel, 1993). These differences in mobility are directly related to mutations at the gene locus that cause amino acid substitutions in the enzyme coded by the gene (Hames and Rickwood, 1981). Differences in the electrostatic charge between the original and substituted amino acid will affect the net charge of the enzyme, and hence its electrophoretic mobility (Avise, J. C. 2004)). Thus, it is possible to relate mobility differences to different alleles at the gene locus for the enzyme in question. These mobility variants are called electromorphs. The unique profile of electromorphs produced for each species of organism is called an electromorph type (ET) (Thimothy et al., 2003).

Enzyme electrophoresis was first used in the study of the population genetics in humans (Harris, et al., 1976) and in Drosophila (Lewontin et al., 1996).the procedure soon became a standard technique in solving issues related to eukaryotic evolutionary biology. Later, it was applied to microorganisms, with extensive work being done on the genetic structure of natural populations of bacteria (Selander, et al., 1986).

The underlying principle of electrophoresis includes the migration of charged molecules in solution due to the influence of an externally applied electric field. The electrophoresis is carried out on a supporting medium. Some commonly used supporting media include: Paper, Cellulose acetate, Agar gel, Starch gel, Agarose gel and Polyacrylamide gel. In Polyacrylamide gel electrophoresis (PAGE), the molecules being analyzed, migrate in an electric field which is imposed on the aqueous solution (buffer) trapped in the matrix of the gel (Castellanos, 2001).

The preference of polyacrylamide over other supporting media is due to the following:

It is chemically inert

Yields transparent gel

Ease of handling the gel

Possibility to alter the pore size of the gel

Starch gel is the most popular support medium for enzyme electrophoresis in population genetic and biochemical systematic studies. This is due to some advantages of starch gel over other support media. At the same time, the starch gel has some disadvantages. Different lots of commercially available hydrolyzed starch supplied by different manufacturers usually differ in composition and may contain differing proportions of amylase and amylopectin, which can affect gelling ability and resolution, quantitative measurement by densitometry. The lack of uniformity of the starch gel matrix also makes it less suitable for densitometric quantity than the polyacrylamide gel. Conventional starch gel stains usually involve volumes of 25 to $50 \mathrm{ml}$, which is about one order more than is required for staining other gels of the same size. Starch gel is more friable than polyacrylamide gels and is not easy to handle (Gibson, et al., 1980).

Flint, et al., (2008), have studied comparison between starch and polyacrylamide gels for the analysis of Listeria monocytogenes using multilocus enzyme electrophoresis. They have reported that the starch gel method distinguished six electrophoretic types whereas the polyacrylamide gel method produced 17 different electrophoretic types. The polyacrylamide gel method was more discriminatory than the starch gel method. 
For the most part, three media are used for enzyme characterization: polyacrylamide, starch, and cellulose acetate. As in all techniques, each has advantages and drawbacks. Cellulose acetate consists in small gels that are sold ready to use (Helena ${ }^{\circledR}$ Laboratories, Beaumont, TX). One has only to soak the gel in the appropriate buffer just before running the electrophoresis. The experiment is very short (20-30 $\mathrm{min})$, and once dried, the gel is as easy to keep and store as a playing card and can be sent by mail. Polyacrylamide and starch gels are more time consuming, but their resolution is generally better. Polyacrylamide would be the best from this point of view (Michel, 2009).

\section{Materials and methods}

1) Extraction buffer, sucrose (50\%), $0.2 \mathrm{M} \mathrm{Tris} \mathrm{HCl}(\mathrm{pH} 7.2)$, EDTA $(64 \mathrm{mg} / 100 \mathrm{ml})$ and double distilled water.

2) See Table 1 for tray buffers.

3) Vertical gel electrophoresis unit, gel casting chamber, glass plates, spacers, combs, clips, side brackets, migration chamber and power pack.

4) Staining tray, any plastic tray can be used. For staining buffers and reagents see Table2.

\subsection{Sampling}

Tail muscle and/or pleopods were taken from live or freshly killed shrimps. All tissues were placed in liquid nitrogen or dry ice upon collection. We can transport on wet ice to lab and it can be stored at $-80^{\circ} \mathrm{C}$ until needed.

\subsection{Extraction of Enzymes}

Adequate portions $(250 \mathrm{mg}$ ) of tissue were first minced and homogenized using a glass homogenizer under cold condition. Using buffer containing sucrose (50\%), $0.2 \mathrm{M}$ Tris $\mathrm{HCl}(\mathrm{pH} 7.2)$, EDTA $(64 \mathrm{mg} / 100 \mathrm{~mL})$. The homogenates were then centrifuged at $10,000 \mathrm{rpm}$ for $20 \mathrm{~min}$ at $4^{\circ} \mathrm{C}$. After the centrifugation, the supernatant was collected and used for further analyses. $100 \mu \mathrm{L}$ aliquots of supernatant is then stored at $-80^{\circ} \mathrm{C}$. Enzyme stability varies with different species, but there is usually insignificant loss of activity after storage at $-80^{\circ} \mathrm{C}$ for 2 months.

\subsection{Electrophoresis}

\subsubsection{Preparation of stock solutions}

First 22 gm of Acrylamide and 0.8 gm of M, N- methylene-bis-Acrylamide are weighed and dissolved in distilled water and make up the volume to $100 \mathrm{ml}$ and filter the solution before use. Then for LGB (lower gel buffer), weigh $18.15 \mathrm{gm}$ of Tris and dissolved it in $20 \mathrm{ml}$ distilled water and adjust the $\mathrm{pH}$ to 8.8 with concentrated $\mathrm{HCl}$. Make up the volume to $100 \mathrm{ml}$ and filter the solution before use. After that, for UGB (upper gel buffer) $6 \mathrm{gm}$ of Tris was weighed and dissolved in $20 \mathrm{ml}$ distilled water and adjust the $\mathrm{pH}$ to 6.8 . Make up the volume to $100 \mathrm{ml}$ and filter the solution before use. TEMED (tetra ethyl methylene diamine) is available as such and APS (Ammonium per sulphate) $1 \%$ should be freshly prepared.

\subsubsection{Preparation of the gel. Gel is prepared in three steps. See Table 3.}

\subsubsection{Polyacrylamide Gel preparation (Native PAGE)}

a. The notched and rectangular plates should be thoroughly washed with detergent and water, cleaned with absolute alcohol and dried before use. Assemble the gel casting chamber using glass plates, spacers and side brackets.

b. Three different solutions have to be prepared, the sealing gel, the lower gel and the upper gel (see Table 3). Since polymerization is an exothermic process, gel temperature during polymerization inevitably leads to distortion of the bands and deterioration of resolution. Therefore the pre cooled lower and upper gel solutions should be used during gel preparation, to minimize heat liberation at the time of polymerization.

c. Sealing gel is poured between the glass plates and allowed to polymerize. The water liberated during the polymerization is blotted using blotting paper.

d. After pouring LGB above the sealing gel up to an approximate height of $9 \mathrm{~cm}$ for gels of $9 \mathrm{~cm} \times 11 \mathrm{~cm}$ it is layered with a few drops of distilled water or n- butanol not only to prevent the contact of atmospheric oxygen with the gel solution but also to obtain a flat gel surface.

e. After complete polymerization, remove the butanol layer and the lower gel should be thoroughly washed with distilled water and later rinsed with upper gel buffer. 
f. Further, remove the remaining buffer at the surface of separating gel and pour the upper gel solution on the upper surface of the lower gel and immediately insert the Teflon comb.

g. After 2 hrs of photo-polymerization, the comb should be removed and the slots should be washed with water to remove traces of unpolymerized upper gel solution.

h. The gel is ready to load or it can be stored overnight at $4{ }^{\circ} \mathrm{C}$ in distilled water.

\subsubsection{Loading the samples}

The gel slots should be blotted and prepared samples have to loaded separately into the sample wells and then layered with tray buffer. For the first well, a pinch of bromophenol blue is added along with the electrode buffer while layering.

The upper and lower buffer tanks of the electrophoretic chamber should be filled with tray buffer.

Assemble the casted gel in the electrophoretic chamber.

\subsubsection{Running conditions}

Connect the unit to a power pack and carry out the electrophoresis at room temperature $\left(25^{\circ} \mathrm{C}\right.$ with 40 volts for 20-30 minutes, later increase to 65 volts by increasing 10 volts every 10 minutes at $4^{\circ} \mathrm{C}$ in the frigid. Continue the electrophoretic run until the tracking dye bromophenol blue migrates to a distance of $7.5 \mathrm{~cm}$ in the separating gel.

\subsection{Staining}

The location of enzymes in the gel after electrophoresis can be determined by the enzymes catalyzing specific reactions with a substrate that produces a colored product. For some enzymes, such as catalase, the substrate is colored instead of the product. The commonest methods of staining are electron transfer dyes and modified histochemical stains. Specific staining methods are shown in Table 2.

a. Add the reactants to the buffer and dissolve. Add MTT and PMS just before the staining mixture is added to the gel.

b. Gently rock the staining tray until the gel floats free in the staining solution. Cover the tray and incubate, in the dark at $37^{\circ} \mathrm{C}$.

c. If an agar overlay is needed, the reactants are mixed with half the volume of buffer. In the other half, melt $0.5 \mathrm{~g}$ of Oxoid No. 1 agar. Allow the agar to cool to $55^{\circ} \mathrm{C}$. Mix both solutions together before pouring over the gel. Preparing the overlay prevents the enzyme in the stain mix and the gel from denaturing. Leave the gel for 2 min on a level surface to set before incubation.

d. Regularly check the development of the enzyme bands until optimum development has occurred. This varies greatly between enzymes depend on the amount of specific enzyme and the type of enzyme in the sample.

e. When staining is complete, score the relative migration of the enzymes by eye or use software.

\section{Results}

The type of analysis carried out on zymogram data depends on the aims of the study in question. Genetic diversity (h) can be calculated using the formula:

$\mathrm{h}=1-\sum \mathrm{X}^{2 \mathrm{i}}[\mathrm{n} /(\mathrm{n}-1)]$

$\mathrm{X}_{\mathrm{i}}=$ frequency of the ith allele at the locus

$\mathrm{n}=$ number of species

$\mathrm{n} /(\mathrm{n}-1)=$ correction for $\mathrm{s}$ mall sample size

Genotypic diversity can be derived from the same formula. In that case $X_{i}$ is the frequency of the ith ET and $n$ is the number of Genetic distance (D) between species or ETs can be calculated using several different coefficients (Sneath and Sokal, 1973). It is usually calculated as the proportion of loci at which dissimilar alleles occur, i.e., the number of mismatches. These coefficients can be either unweighted or weighted. If they are weighted, the contribution of each locus to D is multiplied by the reciprocal of the mean genetic diversity at the locus in the total sample being analyzed. Weighting in this manner emphasises the significance of variation at loci that have low genetic diversity. A variety of statistical methods can be used to produce a graphical representation of the relatedness between isolates or ETs (Sneath and Sokal, 1973). Figure 5 shows a dendrogram of genetic distance between pairs of ETs calculated using the proportion of mismatches method. Figure 6 shows a three-dimensional graph of a principal coordinate analysis of the same data. Both were 
produced by a macro subroutine running on the SAS statistical package (Graves, L. M. et al., 1994). There are many other computer packages available that can be used for the analysis of MEE data (Rodriguez, et al., 1996; Pujol, et al., 1997).

Based on genetic distance matrix, a dendrogram was generated using UPGMA clustering method for PGI zymogram (Fig 1 and 2).

\section{Conclusion}

Writing a protocol on enzymes in 2010 is an interesting challenge. Is this technique not relegated to the status of an ancient proto- type? In the age of real-time polymerase chain reaction (PCR), automatic sequencing, and microarrays, it may seem strange to continue to use this peculiar cuisine with its many toxic coloring agents and questionable recipes. Still, the wealth garnered from the enzyme era is indeed remarkable, if only for its historical significance, and it deserves to be reviewed. Moreover, the advantages offered by enzymes when the technique was born remain valid. This inexpensive and hardy technology can therefore be a salvation for laboratories with few resources, making it possible to conduct very reliable research at low cost. Another reason for not condemning enzymes to the dungeon of is the utility of their dual vision and data congruency. When genetic distance of species is involved, it is reassuring that different types of markers provide convergent results: This is the congruence principle. Using two different types of markers will therefore augment the reliability of the results. Moreover, all things being equal, experience shows that the resolution power of the analysis is greater when doing this: Five enzyme-coding loci and five restriction fragment length polymorphism (RFLP) loci give better results than ten RFLP loci alone. Since the nature of this technology, and even sometimes the mere existence of it, is virtually unknown to many young scientists, I feel it will be useful to start at the very beginning and to expound the main features that make the technique relevant. This will have the advantage of stamping out many preconceived ideas. It is presented as answers to frequently asked questions, drawing on only the main points.

\section{References}

Ausubel FM, Brent R, Kingston RE, Moore DD, Seidman JG, Smith JA, Struhl K, eds. (1993). Current Protocols in Molecular Biology. New York: John Wiley and Sons, Inc.

Avise, J. C. (2004). Molecular Markers, Natural History and Evolution. 2nd ed. Chapman and Hall, New York.

Castellanos-Serra, L. Hardy, E. (2001). Detection of biomolecules in electrophoresis gels with salts of imidasole and zinc. Electorophoresis. 22. 864-873.

Caugant (ed.), Molecular Epidemiology of Microorganisms, Methods in Molecular Biology, Vol. 551.

Flint S.H, Hartley N.J, Avery S.M. Hudson. J.A. (2008). A comparison between starch and polyacrylamide gels for the analysis of Listeria monocytogenes using multilocus enzyme electrophoresis. Letters in Applied Microbiology.22, 123-129.

Gibson, W. C., Marshall, T. F., de, C., and Godfrey, D. G. (1980). Numerical analysis of enzyme polymorphism: a new approach to the epidemiology and taxonomy of trypanosomes. Adv. Parasitol. 18, $175-246$.

Graves, L. M. et al. (1994). Comparison of ribotyping and multilocus enzyme electrophoresis for subtyping of Listeria monocytogenes isolates J. Clin. Microbiol. 32, 2936-2943.

Hames BD, Rickwood D, eds. (1981). Gel Electrophoresis of Proteins: A Practical Approach. Oxford: IRL Press.

Harris, H. and Hopkinson, D. A. (1976). Handbook of Enzyme Electrophoresis in Human Genetics, North Holland Publishing, Amsterdam.

Lewontin,R.C. and Hubby, J. L. (1966). A molecular approach to the study of the hetrozygosity in natural populations. II. Amount of variation and degree of heterozygosity in natural populations of Drosophila pseudoobscura. Genetics 54, 595-609.

Michel Tibayrenc. (2009). Multilocus Enzyme Electrophoresis for Parasites and Other Pathogens. D.A.

Pujol, C., Joly S., Lockhard, S. R., et al. (1997). Parity among the randomly amplified polymorphic DNA method, multilocus enzyme electrophoresis, and southern blot hybridization with the moderately repetitive DNA probe Ca3 for fingerprinting Candida albicans. J.Clin. Microbiol. 35, 2348-2358.

Rodriguez, E., De Meeus, T., Mallie, M., et al. (1996). Multicentric epidemiological study of Aspergillu fumigatus isolates by multilocus enzyme electrophoresis J. Clin. Microbiol. 34, 2559-2568. 
Selander, R. K., Caugant, D. A., Ochman, H., et al. (1986). Methods of multilocus enzyme electrophoresis for bacterial population genetics and systematics. Appl. Environ. Microbiol. 51, 873-884.

Sneath, P. H. A. and Sokal, R. R. (1073). NumericalTaxonomy, W. H. Freeman, San Francisco.

Timothy Stanley and Ian G. Wilson. (2003). Multilocus Enzyme Electrophoresis A Practical Guide. Molecular Biotechnology. Vol. 24, 203 -220.

Table 1. Tray buffers

\begin{tabular}{|l|l|}
\hline Boric acid, NaOH buffer & Tris EDTA borate buffer \\
\hline 18.55 gm boric acid & 10.562 gm Tris \\
2.4 gm of NaOH, & 0.538 gm boric acid \\
Make up to 1 lit with distilled water & 0.372 gm EDTA \\
Adjust pH to 8.65. & 0.664 gm NAD \\
& Make up to 1 lit with distilled water \\
& Adjust pH to 9.0. \\
\hline $\begin{array}{l}\text { Glucose-6-phosphate isomerase (PGI), } \\
\text { Glutamate oxaloacetic transminase (GOT) }\end{array}$ & Arginine phosphokinase (APK) \\
\hline
\end{tabular}


Table 3. Preparation of native gel $(\mu 1)$

\begin{tabular}{|c|c|c|c|c|c|c|}
\hline & \multicolumn{2}{|c|}{ Sealing gel } & \multicolumn{2}{|c|}{ Separating gel } & \multicolumn{2}{|c|}{ Staking gel } \\
\hline & $7.5 \%$ & $5 \%$ & $7.5 \%$ & $5 \%$ & $7.5 \%$ & $5 \%$ \\
\hline Acrylamide & 173 & 173 & 22520 & 1680 & 494 & 330 \\
\hline LGB & 118 & 118 & 1720 & 1724 & ---- & ---- \\
\hline UGB & ---- & ---- & ---- & --- & 494 & 494 \\
\hline Distilled water & 205 & 205 & 3050 & 3890 & 947 & 1012 \\
\hline APS & 7 & 7 & 46 & 46 & 20 & 20 \\
\hline TEMED & 2 & 2 & 5 & 5 & 2 & 2 \\
\hline Polymerization time & \multicolumn{2}{|c|}{$10 \mathrm{~min}$} & \multicolumn{2}{|c|}{$20-30 \mathrm{~min}$} & \multicolumn{2}{|c|}{$10-15 \mathrm{~min}$} \\
\hline
\end{tabular}

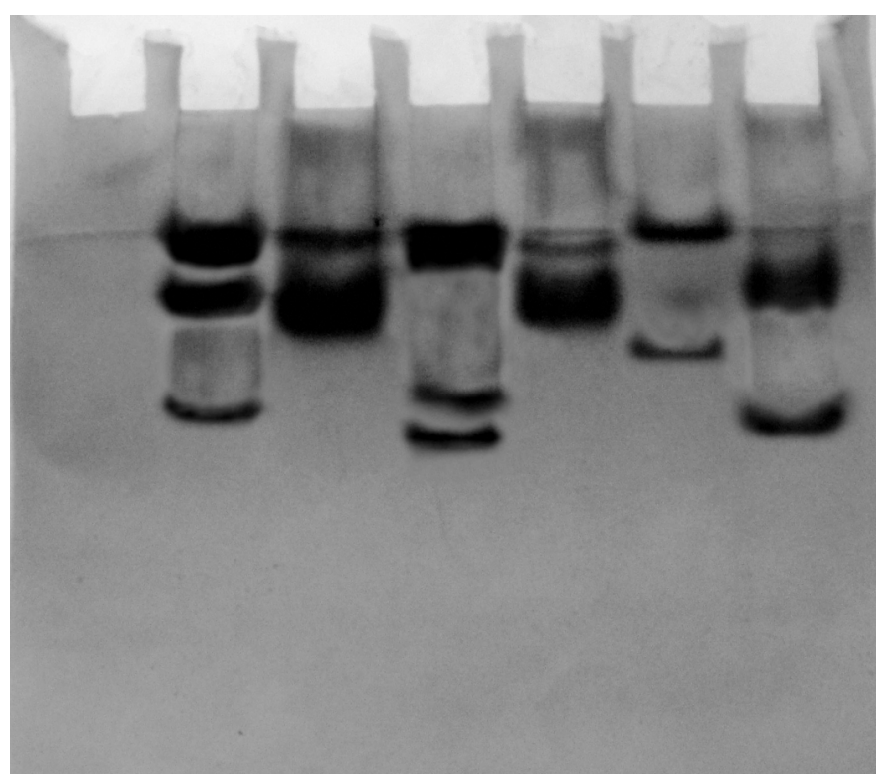

Figure 1. Stained gel of Glucose-6-phosphate isomerase (PGI)

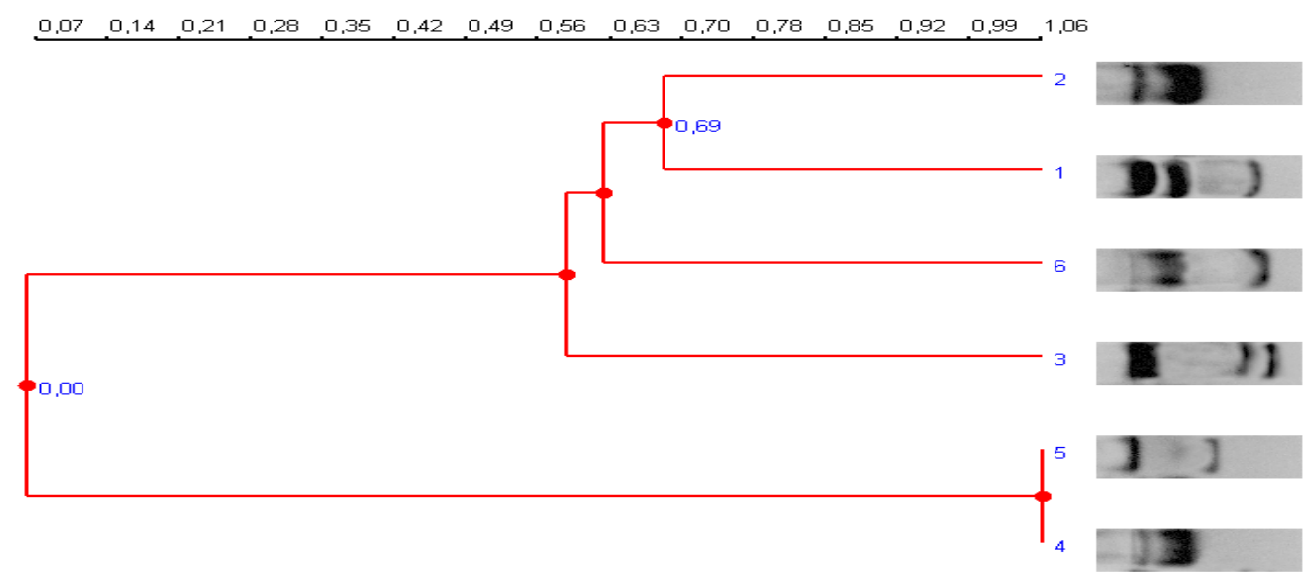

Figure 2. Dendrogram of genetic distance based on UPGMA by AlphaView software.Genetic distance is estimated by moving from left to right across the dendrogram until two lines join. 